\title{
ATTITUDES TOWARDS OLDER PEOPLE IN CROATIAN AND SLOVENIAN NURSING STUDENTS
}

\author{
Jurica Veronek ${ }^{1}$, Maja Bajs Janović ${ }^{2}$ Špiro Janović ${ }^{2}$, Hrvoje Barić ${ }^{3}$, \\ Joca Zurc ${ }^{4} \&$ Zvjezdana Gvozdanović ${ }^{5}$ \\ ${ }^{1}$ University Center Varaždin, University North, Varaždin, Croatia \\ ${ }^{2}$ Department of Psychiatry and Psychological Medicine, University Hospital Center Zagreb, Zagreb, Croatia \\ ${ }^{3}$ Department of Neurosurgery, University Hospital Center Zagreb, Zagreb, Croatia \\ ${ }^{4}$ Graduate School of Education, Okayama University, Okayama, Japan \\ ${ }^{5}$ General County Hospital Našice, Našice, Croatia
}

received: 20.8.2019;

revised: 12.2.2020;

accepted: 27.2 .2020

\section{SUMMARY}

Background: Croatia and Slovenia are neighboring countries with marked differences in high school and undergraduate nursing curricula. The aim was to assess and compare attitudes toward the elderly among undergraduate nursing students in Croatia and Slovenia and identify factors associated with positive/negative attitudes.

Subjects and methods: This was a cross-sectional survey conducted between September, 2017 and July, 2018 among undergraduate nursing students at five higher education institutions: three in Slovenia and two in Croatia. The following data were gathered: age, sex, year of study, previous education, employment status, previous education in gerontolgy, desired professional role after graduating, previous experience with the elderly. Kogan's Attitude Towards Old People Scale (KATOPS) score was the primary outcome measure. Pairwise comparisons were conducted between Croatian and Slovenian students. KATOPS score was dichotomized with values above the $3^{\text {rd }}$ quartile considered excellent - the dichotomized score was used as the dependent variable in a binary logistic regression model.

Results: Overall, 825 students completed the questionnaire, $85.5 \%$ were women, 417 from Slovenia, 408 from Croatia, and $80 \%$ were under 22 years of age (80\%). The average score on the KATOPS was 127.4, 95\% CI 126.6-128.2. Variables associated with excellent scores on the KATOPS, based on the binary regression were: studying in Slovenia (OR=2.05, 95\% CI 1.39-3.03), age group 28-32 years (OR=3.9, 95\% CI 1.53-9.98); previous education gerontic nursing (OR=2.45, 95\% CI 1.34-4.47), and full-time study $(O R=2.12,95 \%$ CI 1.38-3.55). Variables not associated with excellent scores were: being married (OR=0.44, $95 \%$ CI 0.22 $0.92)$ and having previous experience in working with the elderly $(O R=0.5,95 \%$ CI 0.3-0.86).

Conclusion: Attitudes toward old age are mildly positive in Slovenian and Croatian nursing students. Slovenian students have significantly more positive attitudes toward old age and these differences are most probably due to marked differences in undergraduate nursing curricula between the two countries.

Key words: aging - attitudes - nursing

\section{INTRODUCTION}

Positive perception of healthcare professionals positively affects the elderly in terms of their activity and involvement in all societal roles (Alamri \& Xiao 2017). Previous studies have shown that, in general, nurses have positive attitudes towards the elderly; however, they have insufficient levels of knowledge on important issues in hospital settings, socioeconomic determinants of the aging process and specific care of elderly patients (Mellor et al. 2007). Quality of care for the elderly patients was shown to be associated with attitudes of healthcare providers: also, there is an association between attitudes and knowledge in the respective field (Coffey \& Whitehead 2015). Educating health professionals at all levels of education could have a significant impact on change or at least modification of attitudes, if the curriculum is extended to include, apart from theoretical concepts on age and ageing, also practical and communicational skills as important prerequisites of quality care for the elderly (Adibelli \& Kılıç 2013).

So far there have been no studies to research attitudes towards old age and aging in Croatia and Slovenia, and consequently no studies to compare such results between the two countries. An analysis of the high school and higher education curricula in nursing shows that they differ between the two neighboring countries with regard to type and amount of contents on geriatric subjects (Table 1). In general, the data show that, compare to Croatia, higher education undergraduate curricula in Slovenia are more in line with the European directives on the recognition of professional qualifications (2005/36/EC and 2013/55/EU) and the Bologna declaration (European Union 2013, European Ministers in charge of Higher Education 2009).

The aim is to assess and compare attitudes towards advance age and aging in Croatian and Slovenian nursing students and investigate the impact of different factors on these attitudes. 
Table 1. Comparison of nursing high school and higher education curricula in Slovenia and Croatia

\begin{tabular}{|c|c|c|c|c|c|}
\hline \multirow{2}{*}{$\frac{\text { Country }}{\text { High school }}$} & \multicolumn{3}{|c|}{ Slovenia } & \multicolumn{2}{|c|}{ Croatia } \\
\hline & Maribor & Novo Mesto & Ljubljana & Varaždin & Zagreb \\
\hline Length of schooling & 4 years & 4 years & 4 years & 5 years & 5 years \\
\hline School year & 3 & 3 & 3 & 5 & 5 \\
\hline Subject title & $\begin{array}{l}\text { health care } \\
\text { in geriatrics }\end{array}$ & $\begin{array}{l}\text { health care } \\
\text { in geriatrics }\end{array}$ & $\begin{array}{l}\text { health care } \\
\text { in geriatrics }\end{array}$ & $\begin{array}{l}\text { health care } \\
\text { of the elderly }\end{array}$ & $\begin{array}{l}\text { health care } \\
\text { of the elderly }\end{array}$ \\
\hline No. of sessions & $\begin{array}{l}58 \text { lectures } \\
180 \text { praxis }\end{array}$ & & 64 & $\begin{array}{l}34 \text { lectures } \\
102 \text { praxis }\end{array}$ & $\begin{array}{l}34 \text { lectures } \\
102 \text { praxis }\end{array}$ \\
\hline $\begin{array}{l}\text { Higher educa } \\
\text { tion institution }\end{array}$ & $\begin{array}{l}\text { Maribor } \\
\text { University }\end{array}$ & $\begin{array}{l}\text { Novo Mesto } \\
\text { Faculty }\end{array}$ & $\begin{array}{l}\text { Ljubljana } \\
\text { University }\end{array}$ & $\begin{array}{l}\text { University } \\
\text { North }\end{array}$ & $\begin{array}{l}\text { Health University } \\
\text { Zagreb }\end{array}$ \\
\hline Study year & 1 & 2 & 1 & 3 & 3 \\
\hline Semester & 1 & 4 & 2 & 5 & 5 \\
\hline $\begin{array}{l}\text { Compulsory } \\
\text { subject no. } 1\end{array}$ & $\begin{array}{l}\text { Health care } \\
\text { of the elderly } \\
\text { with geriatrics }\end{array}$ & $\begin{array}{c}\text { Health care } \\
\text { of the elderly } \\
\text { with gerontology } \\
\text { and rehabilitation }\end{array}$ & $\begin{array}{c}\text { Health care } \\
\text { of the elderly } \\
\text { and rehabilitation }\end{array}$ & $\begin{array}{l}\text { Health care } \\
\text { of the elderly }\end{array}$ & $\begin{array}{l}\text { Health care } \\
\text { of the elderly }\end{array}$ \\
\hline No. Of sessions & $\begin{array}{c}35 \text { lectures } \\
20 \text { seminars }\end{array}$ & $\begin{array}{c}45 \text { lectures } \\
15 \text { seminars } \\
190 \text { clinical praxis }\end{array}$ & $\begin{array}{c}30 \text { lectures } \\
30 \text { praxis } \\
330 \text { clinical praxis }\end{array}$ & $\begin{array}{c}30 \text { lectures } \\
15 \text { seminars } \\
45 \text { clinical praxis }\end{array}$ & $\begin{array}{c}30 \text { lectures } \\
15 \text { seminars } \\
45 \text { clinical praxis }\end{array}$ \\
\hline Ects & 3 & 9 & 15 & 4 & 4 \\
\hline Study year & 1 & 3 & & & \\
\hline $\begin{array}{l}\text { Compulsory } \\
\text { subject no. } 2\end{array}$ & $\begin{array}{l}\text { Health care in } \\
\text { geriatrics with } \\
\text { optional clinical } \\
\text { qualification }\end{array}$ & / & l & / & l \\
\hline No. of sessions & 320 clinical praxis & / & / & / & / \\
\hline Elective subject & & $\begin{array}{l}\text { Quality of geronto- } \\
\text { logy health care }\end{array}$ & / & / & / \\
\hline No. of sessions & & $\begin{array}{c}30 \text { lectures } \\
15 \text { seminars } \\
90 \text { clinical praxis }\end{array}$ & / & / & / \\
\hline ECTS & 11 & 5 & 1 & 1 & 1 \\
\hline
\end{tabular}

ECTS - European Credit Transfer System

\section{SUBJECTS AND METHODS}

\section{Design and setting}

The study was a cross-sectional survey of attitudes on advanced among undergraduate nursing students at five higher education institutions: two in Croatia an three in Slovenia, between September, 2017 and July, 2018. Hard copies of questionnaires were administered to students in the lecture halls at their educational institutions and a researcher was present during the process in order to resolve any potential ambiguities and uncertainties.

The research was approved by the respective institutional review boards and all participants signed an informed consent to participate in the study. Anonymity was ensured and all data were coded, for protection.

\section{Data gathering}

Each participant was given a booklet containing the following questionnaires: i) administrative and related data questionnaire (age, sex, year of study, previous education, employment status, previous education in gerontolgy, desired professional role after graduating, previous experience with the elderly); ii) Kogan's Attitude Towards Old People Scale (KATOPS) (Kogan 1961).

The questionnaire was tested for cross-cultural adaptation on a smaller subsample of participants from English to Croatian and Slovenian.

\section{Subjects}

The sample were nursing undergraduate students from five higher education institutions: two in Croatia (University North, University Center Varaždin, Undergraduate Nursing Course and Health University Zagreb, Undergraduate Nursing Course) and three in Slovenia (Faculty of Medicine, Ljubljana University, Health Care Undergraduate Course, Novo Mesto Health Faculty, Undergraduate course, and Maribor University, Faculty of Health care, Undergraduate Course). The sample was structured so that the individual subsample sizes were weighted with regard to enrollment quotas at the respective institutions, and then further with regard to year of study. 


\section{Statistical analysis}

Normality was assessed using the KolmogorovSmirnov test. Categorical data were summarized as absolute and relative frequencies and continuous data as means and standard deviations and as medians and interquartile ranges. Outliers were defined as values deviatning more the 1.5 interquartile range. One-was analysis of variance (ANOVA) was used for multiple comparisons of means, with post hoc Bonferroni test. Proportions were compared using the $\chi^{2}$ test. Internal consistency of the KATOPS was estimated by calculating the Cronbach`s $\alpha$. Values $>0.7$ were considered satisfactory. Binary logistic regression analysis was used to asses the association between demographic and educational factors, differing geographic settings (Slovenia vs. Croatia), experience in working with the elderly and excellent scores ( $\geq 3^{\text {rd }}$ quartile, or 135) on the KATOPS. Statistical significance was set at $\mathrm{P}<0.05$. All analyses were performed using the SPSS v24 (IBM SPSS, Armonk, NY, USA).

Table 2. Comparison between Croatian and Slovenian nursing students with regard to sociodemographic characteristics, previous gerontic education and experience

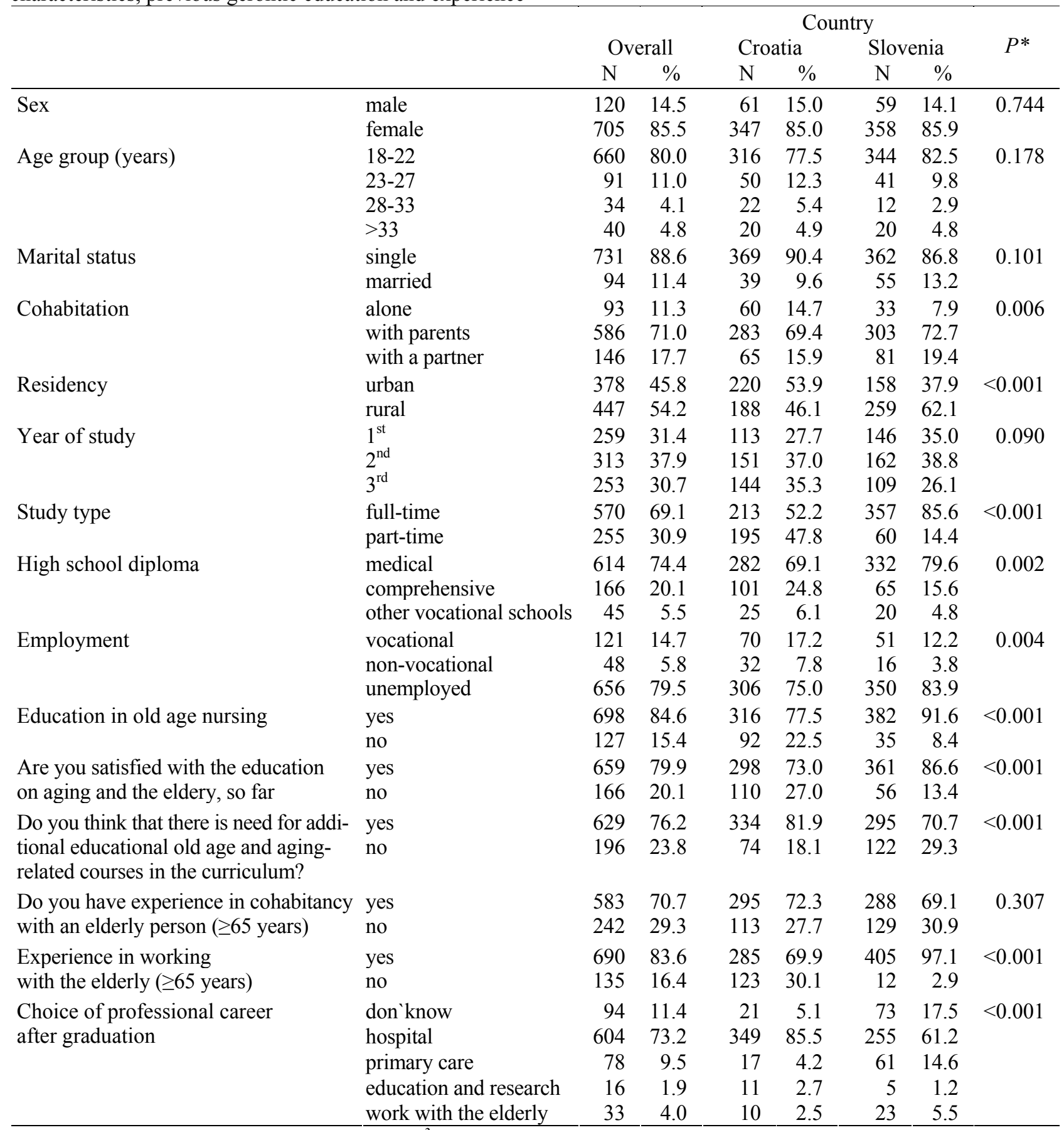

numbers are absolute (relative) frequencies; $* \chi^{2}$-test 


\section{RESULTS}

Overall, 825 students completed the questionnaire, of which $225(27.3 \%)$ were from the Ljubljana University, $213(25.8 \%)$ from the Zagreb University, 195 $(23.6 \%)$ from the University North, 141 (17.1\%) from Novo Mesto, and 51 (6.2\%) from the Maribor University. The majority were women $(85.5 \%)$, and under 22 years of age $(80 \%)$. Married were $11.4 \%$ of participants, and $71 \%$ lived with the parents. More than half $(54.2 \%)$ of them lived in rural setting, and there were roughly equal numbers of participants per study years. Part-time were $30.9 \%$ of students. Roughly three quarters $(74.4 \%)$ of students had medical high school background, and $79.5 \%$ were unemployed at the time of the survey. Education in the field of care for the elderly had $84.6 \%$ participants, and $79.9 \%$ were satisfied with their education on the elderly so far. More than three quarters $(76.2 \%)$ of participants considered that it is necessary to include additional education on the problems of old age and aging into the curriculum. The majority $(83.6 \%)$ of participants had previous experience of working with the elderly (Table 2).

There were no significant differences between Croatian and Slovenian students in age, sex, marital status or experience in cohabitation with the elderly. Between Croatian and Slovenian students there were significant differences in marital status $(\mathrm{P}=0.006)$, place of residence $(\mathrm{P}<0.001)$, proportion of part-time vs. full time students $(\mathrm{P}<0.001)$, students with a comprehensive highschool diploma $(\mathrm{P}=0.002)$, employment status $(\mathrm{P}=0.004)$, education in care for the elderly $(\mathrm{P}<0.001)$, experience in care for the elderly $(\mathrm{P}<0.001)$, opinion on the need for additional educational courses in old age and agingrelated problems $(\mathrm{P}<0.001)$, and choice of professional career after graduation $(\mathrm{P}<0.001)$ (Table 3$)$.

Table 3. Scores on the Kogan`s Attitude Towards Old People Scale: univariate comparisons

\begin{tabular}{|c|c|c|c|c|c|c|c|}
\hline \multirow[b]{2}{*}{ Country } & \multirow[b]{2}{*}{ Croatia } & \multirow{2}{*}{$\frac{\mathrm{N}}{408}$} & \multirow{2}{*}{$\frac{\mu}{125.1}$} & \multirow{2}{*}{$\frac{\mathrm{SD}}{11.0}$} & \multicolumn{2}{|c|}{$95 \% \mathrm{CI}$} & \multirow[b]{2}{*}{$<0.001$} \\
\hline & & & & & 124.0 & 126.2 & \\
\hline & Slovenia & 417 & 129.6 & 12.3 & 128.4 & 130.8 & \\
\hline \multirow[t]{2}{*}{ Sex } & male & 120 & 125.2 & 11.1 & 123.2 & 127.3 & 0.032 \\
\hline & female & 705 & 127.7 & 11.9 & 126.9 & 128.6 & \\
\hline \multirow[t]{4}{*}{ Age group (years) } & $18-22$ & 660 & 127.5 & 12.0 & 126.6 & 128.5 & 0.465 \\
\hline & $23-27$ & 91 & 126.4 & 11.5 & 123.9 & 128.8 & \\
\hline & $28-33$ & 34 & 129.2 & 10.9 & 125.4 & 133.1 & \\
\hline & $>33$ & 40 & 125.5 & 10.6 & 122.1 & 128.9 & \\
\hline \multirow[t]{2}{*}{ Marital status } & single & 731 & 127.4 & 12.1 & 126.5 & 128.3 & 0.746 \\
\hline & married & 94 & 127.0 & 9.9 & 124.9 & 129.0 & \\
\hline \multirow[t]{3}{*}{ Cohabitation } & alone & 93 & 125.9 & 10.7 & 123.8 & 128.2 & 0.274 \\
\hline & with parents & 586 & 127.8 & 12.3 & 126.8 & 128.8 & \\
\hline & with a partner & 146 & 126.6 & 10.7 & 124.9 & 128.4 & \\
\hline \multirow[t]{2}{*}{ Residency } & urban & 378 & 126.3 & 11.8 & 125.1 & 127.4 & 0.012 \\
\hline & rural & 447 & 128.3 & 11.9 & 127.2 & 129.4 & \\
\hline \multirow[t]{3}{*}{ Year of study } & $1^{\text {st }}$ & 259 & 127.8 & 11.8 & 126.3 & 129.2 & 0.086 \\
\hline & $2^{\text {nd }}$ & 313 & 126.2 & 12.2 & 124.9 & 127.6 & \\
\hline & $3^{\text {rd }}$ & 253 & 128.4 & 11.5 & 126.9 & 129.8 & \\
\hline \multirow[t]{2}{*}{ Study type } & full-time & 570 & 128.8 & 12.2 & 127.8 & 129.8 & $<0.001$ \\
\hline & part-time & 255 & 124.2 & 10.5 & 122.9 & 125.5 & \\
\hline \multirow[t]{3}{*}{ High school diploma } & medical & 614 & 127.9 & 12.2 & 126.9 & 128.8 & 0.111 \\
\hline & comprehensive & 166 & 126.3 & 11.0 & 124.6 & 127.9 & \\
\hline & other vocational schools & 45 & 124.9 & 9.5 & 122.1 & 127.8 & \\
\hline \multirow[t]{3}{*}{ Employment } & vocational & 121 & 124.6 & 11.1 & 122.6 & 126.6 & 0.005 \\
\hline & non-vocational & 48 & 125.4 & 12.3 & 121.8 & 129.0 & \\
\hline & unemployed & 656 & 128.0 & 11.9 & 127.1 & 129.0 & \\
\hline \multirow{2}{*}{$\begin{array}{l}\text { Previous education } \\
\text { in old age nursing }\end{array}$} & yes & 698 & 128.0 & 11.9 & 127.1 & 128.9 & 0.001 \\
\hline & no & 127 & 124.1 & 11.2 & 122.1 & 126.0 & \\
\hline \multirow{2}{*}{$\begin{array}{l}\text { Experience in working } \\
\text { with the elderly ( } \geq 65 \text { years) }\end{array}$} & yes & 690 & 127.7 & 12.0 & 126.8 & 128.6 & 0.052 \\
\hline & no & 135 & 125.6 & 11.16 & 123.7 & 127.5 & \\
\hline \multirow{5}{*}{$\begin{array}{l}\text { Choice of professional career } \\
\text { after graduation }\end{array}$} & don`know & 94 & 128.1 & 10.1 & 126.1 & 130.2 & 0.001 \\
\hline & hospital & 604 & 126.6 & 11.8 & 125.7 & 127.6 & \\
\hline & primary care & 78 & 131.0 & 14.3 & 127.8 & 134.2 & \\
\hline & education and research & 16 & 122.6 & 8.8 & 117.9 & 127.3 & \\
\hline & work with the elderly & 33 & 132.5 & 10.3 & 128.8 & 136.2 & \\
\hline
\end{tabular}


Table 4. Results of the binary logistic regression analysis (backward conditional stepwise) with excellent attitudes toward old people (Kogan`s score $\geq 3^{\text {rd }}$ quartile, or 135) set as dependent variable

\begin{tabular}{|c|c|c|c|c|c|c|}
\hline \multirow{2}{*}{\multicolumn{2}{|c|}{ Slovenia vs. Croatia }} & $\mathrm{B}$ & S.E. & OR & $95 \% \mathrm{CI}$ & $P$ \\
\hline & & 0.719 & 0.198 & 2.05 & $1.39-3.03$ & $<0.001$ \\
\hline \multirow[t]{4}{*}{ Age group: } & $18-22$ (ref) & & & & & 0.040 \\
\hline & $23-27$ & 0.288 & 0.290 & 1.33 & $0.76-2.36$ & 0.321 \\
\hline & $28-32$ & 1.362 & 0.479 & 3.90 & $1.53-9.99$ & 0.004 \\
\hline & $>33$ & 0.792 & 0.596 & 2.21 & $0.69-7.10$ & 0.184 \\
\hline \multicolumn{2}{|l|}{ Married } & -0.811 & 0.370 & 0.44 & $0.22-0.92$ & 0.028 \\
\hline \multicolumn{2}{|c|}{ Full time study } & 0.756 & 0.255 & 2.12 & $1.38-3.55$ & 0.003 \\
\hline \multirow{2}{*}{\multicolumn{2}{|c|}{ Previous education in gerontic nursing }} & 0.898 & 0.306 & 2.45 & $1.35-4.47$ & 0.003 \\
\hline & & -0.682 & 0.271 & 0.51 & $0.30-0.86$ & 0.012 \\
\hline
\end{tabular}

OR - odds ratio; CI - confidence interval

KATOPS showed acceptable internal consistency (Chronbach $\alpha=0.72$ ). The average score on the KATOPS was $127.4 \pm 11.9,95 \%$ CI 126.6-128.2. Scores on the KATOPS were dichotomized so that values above the $3^{\text {rd }}$ quartile $(>135)$ considered excellent. The binary outcome was set as the dependent variable in the binary logistic regression, and predictor variables were all variables included in the univariate comparisons. After a stepwise backward analysis, 6 variables were identified as having statistical significance and were retained in the model (Table 4). Compared to Croatian nursing students, Slovenian students had an odds ratio (OR) of 2.05 (95\% CI 1.39-3.03) of achieving scores $\geq 135$ on the KATOPS. Other significant variables were: age group 28-32 years (ref. group $<22$ years) $\mathrm{OR}=3.9(95 \% \mathrm{CI}$ 1.53-9.98); having previous education in old age nursing OR $=2.45(95 \%$ CI 1.34-4.47); being enroled in a full-time study course OR=2.12 (95\% CI 1.38-3.55); being married $\mathrm{OR}=0.44,95 \% \mathrm{CI} \quad 0.22-0.92$; having previous experience in working with the elderly $\mathrm{OR}=0.5,95 \%$ CI $0.3-0.86$ (Table 4). The model was statistically significant $(\mathrm{P}<0.001)$; however, it explained only $8.7 \%$ of variance.

\section{DISCUSSION}

In the current study, most participants had a previous education in gerontic care and most were satisfied with the education. Regardless of the previous education and satisfaction with it, nearly three quarters of participants think that additional courses in the field should be implemented into the curriculum, which might point to a rising awareness of less than optimal education on gerontic nursing. On the other hand, the finding is highly probably due to Hawthorne effect. Education is a mechanism of proven efficacy for acquiring new approaches and positive attitudes of health professionals toward the elderly (Rodgers \& Gilmour 2011, Milutinovic et al. 2015). Coffey \& Whitehead performed a systematic review on the subject and showed that most published research found an association between education and knowledge towards ageing, which can in turn impact improvement of attitudes toward aging and spark interest in working with the elderly (Coffey \& Whitehead 2015). Likewise, lack of knowledge is associated with negative attitudes and with lack of gerontic education in undergraduate nursing courses.

Most of the participants in our study had an experience of working or living with elderly people. Working experience with a certain population and/or a problem usually has a positive effect on attitudes and clearing prejudice, as was shown by previous research (Ross et al. 2015). Since more than half of the subjects reported living in a rural area, or with a primary family, the high proportion of subjects having an experience of cohabitation with the elderly is expected.

When asked about future professional goals, most participants in our study opted for hospital (clinical) work and a minority for work with the elderly. Although not explicitly, the participants in this study displayed a lack of motivation for work with gerontic patients, regardless of their past experience with the elderly. If the level of motivation for working with the elderly is so low, then a highly plausible explanation for a high proportion of students expressing need for further education on the topic is that they gave socially desirable answers. A previous study showed that students who gave higher grades with regard to their working environment in a gerontic nursing home had more positive attitudes towards the elderly, yet, despite their positive attitudes, they were reluctant to work with the elderly, because of unfavorable previous experiences, which include difficulties in bonding and communication and a perception of the work as being depressive and monotonous (Henderson 2008). Among many other factors that might affect the attitudes of nursing students, important ones are stereotypes and myths about the general perception of the elderly. These individuals are often perceived as being uninteresting, non-tolerant and nonproductive (Deasey 2014). Also, religious and cultural factors play a role by moderating the upbringing, relationships with the elderly and forming of first attitudes of the young within families. A study by Koskinen et al. showed that students perceive geronotoly as an unwanted profession, which causes a drop in interest for the discipline and thereby leads to negative attitudes 
despite the fact that this specialization leads to future employment opportunities (Koskinen et al. 2014).

Kogan`s Attitude Towards Old People Scale (KATOPS) was used to asses attitudes of nursing students, and it overall showed mild positive attitudes. The highest average grades (the most positive attitudes) were calculated for items: i) "Most old people are really no different from anybody else; they're as easy to understand as younger people"; and ii) "One of the most interesting and entertaining qualities of most old people is their accounts of their past experiences." Positive scores on these two attitudes point to underlying mature psychological mechanisms in respondents - rationalization and humor, which can be interpreted as maturity of students when dealing with problems of ageing and the elderly.

Less favorable attitudes (average score below 3.0) were reported on the following questions: i) "Most old people are constantly complaining about the behavior of the younger generation"; ii) "One seldom hears old people complaining about the behavior of the younger generation"; and iii) "Most old people get set in their ways and are unable to change."

Attitudes on intergenerational behavior, relationships between the young and the old, are expected projections of the examinees, who grow it from their personal experience, but also from collective experiences of their immediate communities. Intergenerational relationships are currently amidst a major change from traditional models of unquestionable respect towards the authority of the elderly in all aspects - family, work and community - to a modern, team-like or democratic approach, which is specific for its division of roles between the young and the elderly. The new model of a relationship with the elderly is not necessarily authoritative, but is based more on a specific contribution of an elderly person in roles which are appropriate or possible for functioning of a business or family community. Nevertheless, it seems as first glance that the examinees in our study have acquired strict traditional views on intergenerational conflicts, and less about intergenerational exchange and cooperation. It is exactly these attitudes that are starting points of any educational programs in gerontology, as they point primarily to critical points as sources of negativity and potentially even conflict.

A study by Lee reported that in general students have more positive, than negative, attitudes toward old people (Lee 2009). A study by Zambrini et al. on first year healthcare students showed that more than half of the students have positive attitudes toward the elderly (Zambrini et al. 2008). A study by Celik et al., on nursing students, showed that students have positive attitudes toward the elderly and are prone to working with them in the future, although they consider the aging process to be a negative phenomenon (Celik et al 2010). The reason for such a perception might be due to the fact that most of the elderly in the country (Turkey) where the study was conducted live a non-active and non-productive lifestyle. Similar findings were reported by Strugala (Strugala 2016).

In univariate comparisons we found no differences in attitudes with regard to the following variables: age, marital status, residential status, study year and high school diploma (Table 3 and 4). Significant differences in attitudes toward the elderly were found between Croatian and Slovenian students: Slovenian students were more likely to have excellent scores on univariate and multivariate analysis. Also, examinees with previous gerontic nursing education have higher attitude scores. The differences between countries are thus expected, given the major qualitative and quantitative curricular differences which are shown in Table 1. Previous studies have demonstrated the association between educational programs on the attitudes toward old people (Zverev 2012). Female students in our study had significantly more positive attitudes toward old people than male students, although the difference was not statistically significant in the regression model. Similar findings were observed between rural and urban-residing students and employed and nonemployed students. Students enrolled in a full-time study course had higher attitude scores than the parttime students. This might be due to the fact that parttime students are often vocationally employed and it is possible than clinical practice might be a generator of less positive, or even skeptical attitudes towards the patients (old people). Previous education in gerontic nursing was shown to be associated with higher attitude scores on both the univariate and regression analysis. Personal experience in working with the elderly was not shown to be associated with attitude scores on the univariate analysis; however, the regression analysis revealed such experience is associated with lower attitude scores. Similar was shown for marital status. Finally, regression analysis showed that being in the age group 28-32 years was associated with higher attitude scores, although the difference was not significant in the univariate analysis.

This study has two major limitations. First of them is that the cross-cultural adaptation of the primary outcome measuring instrument (Kogan`s Attitude Toward Old People Scale) was not published before the initiation of this study. Therefore, we performed an ad hoc small pilot study to verify consistency and reliability of the Croatian and Slovenian versions of the instrument. The results of the analysis show that the instrument can be used in Croatian and Slovenianspeaking population; however, a formal inquiry is warranted, meeting all prescribed steps of a crosscultural adaptation. The second limitation is due to inherent nature of the data gathering process via a questionnaire. Namely, as was evident in some of the scores, the respondents might have provided answers perceived by them as being socially desirable, rather than describing their actual attitudes. 


\section{CONCLUSION}

Attitudes toward old age are mildly positive in Slovenian and Croatian nursing students alike. Slovenian students have significantly more positive attitudes toward old age and these differences are most probably due to marked differences in undergraduate nursing curricula between the two countries. As shown by multivariate analysis, other factors associated with more positive attitudes toward old age are age, full-time (vs. part-time) studying, and previous education in gerontic nursing. Factors associated with more negative attitudes are positive marital status and previous work experience with the elderly. The results demonstrate the significant impact of undergraduate and high school nursing curricula on the attitudes toward the elderly and should therefore prompt the responsible authorities and professionals to change the gerontic nursing curricula in order for them to meet the modern standards.

\section{Acknowledgements: None.}

Conflict of interest: None to declare.

\section{Contribution of individual authors:}

Jurica Veronek: design of the study, literature searches and analyses, interpretation of data, manuscript writing.

Maja Bajs Janovic: design of the study, recruitment and collection of data, statistical analyses, manuscript writing.

Spiro Janovic: recruitment and collection of data, statistical analyses, writing of the report.

Hrvoje Baric: literature searches and analyses, interpretation of data, writing of the report.

Joca Zurc \& Zvjezdana Gvozdanovic: interpretation of data, statistical analyses, writing of the report.

\section{References}

1. Adibelli D, Kılıç D: Difficulties experienced by nurses in older patient care and their attitudes toward the older patients. Nurse Educ Today 2013; 33:1074-1078

2. Alamri B, Xiao L: Health professionals' knowledge and attitudes toward older people in primary care in Saudi Arabia. Saudi Med J 2017; 38:229-236

3. Bernardini Zambrini D, Moraru M, Hanna M, Kalache A, Macias Nuñez J: Attitudes toward the elderly among students of health care related studies at the University of Salamanca, Spain. J Contin Educ Health Prof 2008; 28:86-90
4. Celik SS, Kapucu S, Tuna Z, Akkus Y: Views and attitudes of nursing students towards ageing and older patients. Aust J Adv Nurs 2010; 27:24

5. Coffey A, Whitehead N: Healthcare assistants' attitudes towards older people and their knowledge about ageing. Nurs Older People 2015; 27:24-30

6. Deasey D, Kable A, Jeong S: Influence of nurses' knowledge of ageing and attitudes towards older people on therapeutic interactions in emergency care: A literature review. Australas J Ageing 2014; 33:229-236

7. Directive 2013/55/EU of the European Parliament and of the Council of 20 November 2013 amending Directive 2005/36/EC on the recognition of professional qualifications and Regulation (EU) No 1024/2012 on administrative cooperation through the Internal Market Information System ('the IMI Regulation') Text with EEA relevance. Official Journal of the European Union 2013; 354:132-171

8. European Ministers in charge of Higher Education. The Bologna Declaration of 19 June 1999: Joint declaration of the European Ministers of Education, 1999

9. Henderson J, Xiao L, Siegloff L, Kelton M, Paterson J: 'Older people have lived their lives': First year nursing students' attitudes towards older people. Contemp Nurse 2008; 30:32-45

10. Kogan N: Attitudes toward old people: The development of a scale and an examination of correlates. J Abnorm Soc Psychol 1961; 62:44-54

11. Koskinen S, Salminen L, Stolt M, Leino-Kilpi H: The education received by nursing students regarding nursing older people: a scoping literature review. Scand J Caring Sci 2014; 29:15-29

12. Lee Y: Measures of Student Attitudes on Aging. Educational Gerontology 2009; 35:121-134

13. Mellor P, Greenhill J, Chew D: Nurses' attitudes toward elderly people and knowledge of gerontic care in a multipurpose health service (MPHS) Aust J Adv Nurs 2007; 24:37-41

14. Milutinovic D, Simin D, Kacavendic J, Turkulov V: Knowledge and attitudes of health care science students toward older people. Med Pregl 2015; 68:382-386

15. Randler C, Vollmer C, Wilhelm D, Flessner M, Hummel E: Attitudes Towards the Elderly Among German Adolescents. Educational Gerontology 2013; 40:230-238

16. Ross L, Jennings P, Williams B: Experience, knowledge and attitudes: Are paramedic students prepared to care for older patients? Educational Gerontology 2015; 42:241-252

17. Strugala M: Attitudes Towards the Elderly among Nursing Students in Poland-Initial Findings. J Gerontol Geriatr Res 2016; 5:279

18. Zverev Y: Attitude Towards Older People Among Malawian Medical and Nursing Students. Educational Gerontology 2012; 39:57-66

19. Vivien Rodgers R, GDGN M: Shaping student nurses' attitudes towards older people through learning and experience. Nurs Prax NZ 2011; 27:13

Correspondence:

Jurica Veronek, PhD

University Center Varaždin, University North

42000 Varaždin, Croatia

E-mail:jurica.veronek@unin.hr 